\title{
AN APPROACH TO BALANCE STATE OF CHARGES OF DISTRIBUTED BATTERIES IN VIRTUAL POWER PLANTS OF DC DISTRIBUTION NETWORK
}

\author{
Nguyen Huu Duc \\ Department of Renewable Energy, Faculty of Energy Technology, \\ Electric Power University, 235-Hoang Quoc Viet, Ha Noi, Viet Nam \\ Email:ducnh@epu.edu.vn
}

Received: 20 September 2016; Accepted for publication: 16 December 2017

\begin{abstract}
Small distributed energy sources could be aggregated to form a virtual power plant (VPP) in order to overall improve technical and market issues. VPPs should be composed of several distributed batteries (DB) to solve the problem of intermittency due to wind and solar. This paper presents an approach to balance state of charge batteries. It is therefore to improve the lifetime of batteries in VPPs. According to the proposed method, the real-time SOC of DB will be tracking on the balancing SOC determined in VPP. During operation, the difference of SOC among DBs will be shrunk and finally the share of exchange power among DB is equal. Moreover, the duration time to achieve the balancing SOC can be determined by adjusting the exponent parameter of SOC in the presented function.
\end{abstract}

Keywords: droop control, virtual power plant, SOC, battery.

Classification numbers: 2.8.3, 3.4.1.

\section{INTRODUCTION}

With the strong growth of distributed renewable energy sources (DRES), virtual power plants have been considered an efficient solution to integrate such DRES. VPPs can facilitate integration of a large number of small-scale DRES [1-3]. Several VPPs have been deployed in The Netherlands, Belgium, the UK and Germany [4-6]. In such VPPs, it could be included different distributed energy storage systems (DESS).

DRES are usually combined with DESS in order to solve intermittent issues caused by weather change. The advantages of the coordination between DESSs with RES are shown in [79]. Authors in [10] introduce the operational method in the isolated wind-solar-battery system. This strategy is to minimize changes of operation modes of battery, thus enhance the life time of battery. While paper [11] proposes a scheduling strategy for battery in order to obtain both optimal harvest of RES and longer life time of battery.

One of the most interests in VPPs is that to ensure the equal power sharing among DESSs. The control system of a DESS is normally a three-level control scheme which is the 
management system of battery (BMS); the power control system of converter (PCCS) and the distribution management system (DMS). The function of DMS is to optimally operate VPP. The objective of the BMS is to ensure the balance of output voltage and SOC of each cell in the battery string [12-14]. It is notice that BMS is to balance SOC of each cell but not for different DESSs. Therefore, the function of PCCS is to balance SOC among different DESSs. Authors in [15] introduce cascade H-bridges between converters to balance SOCs. While [16] proposes using a low-pass filter to improve load distribution among DESS. However, all presented above methods are centralized control systems, thus it does not match with the decentralized and distributed characteristic of VPPs.

In this paper, an approach is proposed in order to deal with this challenge. In accordance with this proposed control, the balancing SOC among BESSs can be achieved, thus life time of BESSs could be improved. Meanwhile, this presented control is based on decentralized concept without communication requirement between different DBSSs. Following the introduction section, the general configuration of VPP and its control will be shown in section 3. Modeling of DBSS and the voltage droop method is briefly revised. Section 4 presents the proposed control method to balance BESSs and its analysis. Numerical simulation is performed to realize the proposed method in section 5. Section 6 provides conclusions.

\section{NOMENCLATURE}

$\mathrm{AVR}_{\text {charge }, i}: \quad$ Adaptive virtual resistance in charge process for BESS $\mathrm{i}$,

$\mathrm{AVR}_{\text {discharge }, i}$ : Adaptive virtual resistance in discharge process for BESS i,

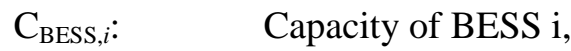

$C_{1}$ : Overvoltage capacitance,

$P_{\text {rate }, i}: \quad$ The power rate of each converter connected to BESS i,

$\mathrm{R}_{\mathrm{VR}}$ : $\quad$ Virtual resistance,

$R_{2}: \quad$ Internal resistance,

$R_{1}: \quad$ Overvoltage resistance,

$\operatorname{SOC}_{i}(t): \quad$ Real-time SOC of BESS $i$,

$\mathrm{SOC}_{\text {min, }, i}$ The minimum SOC of BESS i,

$\mathrm{SOC}_{\max , i}: \quad$ The maximum SOC of BESS i,

SOC $_{\text {high }, i}: \quad$ The high level SOC of BESS i,

$\mathrm{SOC}_{\text {low }, i}$ : The lower level SOC of BESS $\mathrm{i}$,

$\mathrm{I}_{\mathrm{BESS}, i}(t): \quad$ Output current of BESS $i$,

$\mathrm{I}_{\text {ext }}$ : Total exchange current of all BESS with the dc grid,

$\mathrm{V}_{\text {dcdroop }, i}$ : The dc voltage reference from the dc droop control loop,

$\mathrm{V}_{\text {dcref }, i}$ : $\quad$ The dc voltage reference for the BESS i,

$\mathrm{V}_{\mathrm{dc} 0}$ : The dc voltage at PCC,

$\eta_{i}: \quad$ Charge or discharge efficient of BESS,

$\triangle \mathrm{SOC}_{\mathrm{oper}, i}$ : Operation range of $\mathrm{SOC}_{i}$ for BESS $\mathrm{i}$,

$\triangle \mathrm{SOC}_{\mathrm{opt}, \mathrm{i}}: \quad$ Difference between real-time SOC and optimal $\mathrm{SOC}_{\mathrm{opt}}$ for BESS $\mathrm{i}$, 
$\triangle \mathrm{SOC}_{\min , i}: \quad$ Difference between real-time SOC and minimal $\mathrm{SOC}_{\min }$ for BESS i,

$\Delta \mathrm{V}_{\mathrm{dcmin}, i}$ : Difference between the dc voltage reference $\mathrm{V}_{\mathrm{dcref}}$ and the minimum dc voltage,

$\Delta \mathrm{V}_{\mathrm{dcmax}, i}: \quad$ Difference between the maximal dc voltage and dc voltage reference $\mathrm{V}_{\mathrm{dcref}}$,

$\Delta \mathrm{V}_{\mathrm{dc} \text {,margin: }}$ The design margin which is the acceptable deviation of the dc voltage that BESS could not response.

\section{ARCHITECTURE OF A VIRTUAL POWER PLANT}

\subsection{Virtual Power Plant Concept}

There are numerous publications on operation strategies and control system of VPP. Fig. 1 shows a configuration of a VPP that will be studied in this paper. This VPP includes a wind power source (WECS), a PV source, and two DESSs, loads and converters connecting to distributed units. It is proposed that VPP uses a dc links to connect distributed units. The WECS is integrated to dc links through a buck converter. The PV system is composed of a PV array and a buck converter. DESSs are connected to dc links through bi-directional buck converters. These distributed generations are attached to the telecommunication network that is responsible for collecting data and sending control signals.

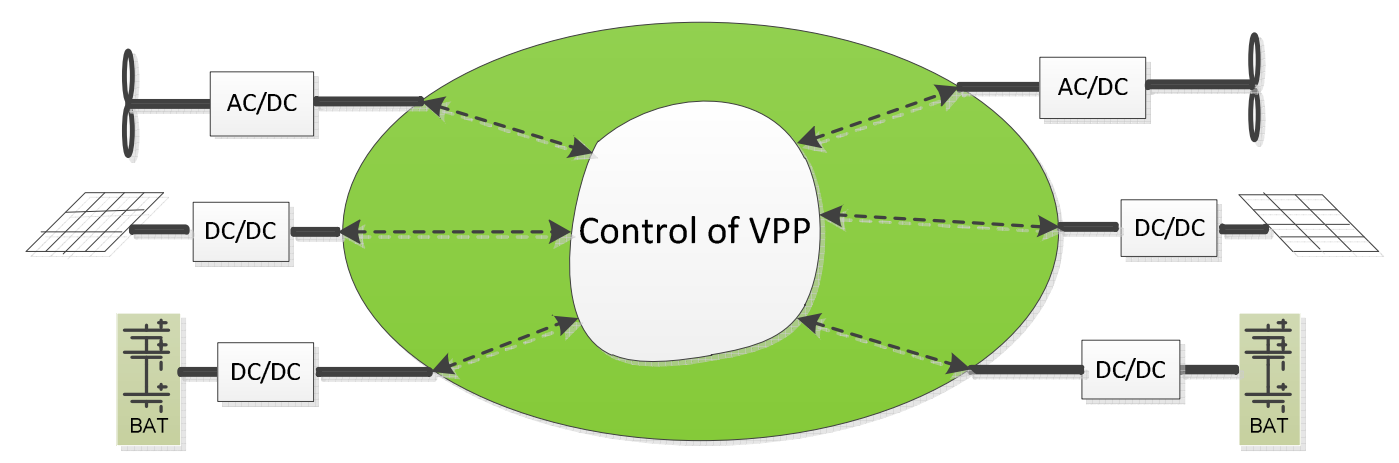

Figure 1. Configuration of a VPP

The control system of VPP is hierarchical and included three levels. The first is the local controllers; the second level is micro-grid central controllers (MGCC); and the highest level is the decentralized energy management system (DESM). In the scope of this paper, the first control level is studied. Basically, the common dc voltage will be kept at the desired value by regulating output powers of DESSs in the VPP according to the adaptive dc droop control approach which will be presented in section IV.

\subsection{Model of the battery energy storage system (BESS)}

As aforementioned in previous section, the purpose of the research is to propose an adaptive coordinated droop control for BESSs in VPP applications. Hence, Fig. 2 briefly shows modeling of BESS. Because the model of BESS in [17] can represent essential characteristics, thus it will be used in this research. The battery parameters are modelling as functions of the open-circuit voltage that relating to SOC. The list of the parameters is provided in section II. 


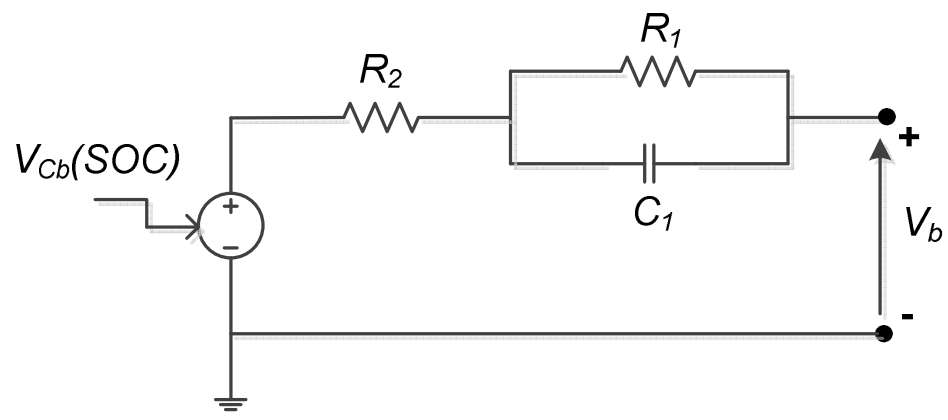

Figure 2. Simplified model of battery.

The SOC of battery can be determined as:

$$
\operatorname{SOC}_{i}(t)=\operatorname{SOC}_{i}(0)-\int_{0}^{t} \eta \frac{i_{B a t, i}(\tau)}{C_{B a t, i}} d \tau
$$

where $i_{B a t, i}$ is the battery current, $\operatorname{SOC}_{i}(0)$ is the initial value $\mathrm{SOC}$ of $\mathrm{BESS}_{i}, \mathrm{C}_{\mathrm{Bat}, i}$ is the capacity of battery, $\eta$ is the charging or discharging efficiency.

\section{A PROPOSED DROOP CONTROL CONCEPT BASED ON SOC}

\subsection{The SOC-Balancing based Adaptive Virtual Resistance}

In such architecture of the proposed VPP, dc voltage signals are used to control distributed batteries. The control scheme applied for distributed batteries is the dc droop control, so their output power will depend on their virtual resistances. It is not proper to use the same virtual resistance for two batteries with different capacities or initial SOCs. Because good life-cycle for batteries is expected as small depth of discharge (DOD) as possible [18], therefore, the best solution is to try and equalize the SOCs of all batteries in the VPP applications. In order to do that, a battery with the higher SOC should be commonly discharged at the faster rate. For charging process, the contrary consideration should be taken into account. The reference values of de voltage can be calculated by adjusting the adaptive virtual resistance as follows.

$$
V_{\text {dcdroop }}=V_{\text {dcref }}-A V R \times I_{B E S S}
$$

To achieve this objective, an SOC-based adaptive virtual resistance (AVR) is proposed. The value of $\mathrm{AVR}_{\mathrm{i}}$ should correspond to the real-time SOC and capacity of the battery $i$. Higher $\mathrm{AVR}_{\mathrm{i}}$ will force higher discharge rate and vice versa, and the similar way with capacity. Therefore, in the discharging process, a higher $\mathrm{AVR}_{\mathrm{i}}$ should be given to a battery with lower SOC. On the other hand, during charging process, higher $\mathrm{AVR}_{\mathrm{i}}$ should be given to a battery with higher SOC. Furthermore, capacity of battery should also be taken into $\mathrm{AVR}_{\mathrm{i}}$. As a result, a symmetric function determining $\mathrm{AVR}_{\mathrm{i}}$ for charge and discharge process respectively can be expressed as follows.

$$
A V R_{\text {charg } e, i}=m_{0} \frac{C_{B a t, i}}{C_{\text {max }}} \Delta S O C_{\text {min }, i}^{q}
$$




$$
\begin{aligned}
A V R_{\text {ch } \arg e, i} & =K_{0} \Delta S O C_{\min , i}^{q} \\
A V R_{\text {disch } \arg e, i} & =m_{0} \frac{C_{B a t, i}}{C_{\max }} \Delta S O C_{\min , i}^{-q} \\
A V R_{\text {disch } \arg e, i} & =K_{o} \Delta S O C_{\min , i}^{-q}
\end{aligned}
$$

where:

$$
\begin{aligned}
K_{0} & =m_{0} \frac{C_{B a t, i}}{C_{\max }} \\
\Delta S O C_{\min , i}(t) & =S O C_{i}(t)-S O C_{\min , i}
\end{aligned}
$$

According to this control strategy, BESS with higher real-time SOC will have higher $\mathrm{AVR}_{\mathrm{i}, \text { charge }}$ and smaller $\mathrm{AVR}_{\mathrm{i}, \mathrm{disch}}$ arge. Therefore, the BESS with higher SOC will discharge faster charge slower. As a result, BESSs will have the same SOC.

\subsection{SOC Balancing Speed}

As aforementioned, with the $\mathrm{AVR}_{\mathrm{i}}$ concept, the energy stored in DESSs with higher reduces faster than that in DESSs with lower SOC. The SOC balancing speed can be determined by selected the suitable exponent coefficient $q$ in (3) \& (5). At the point of common coupling (PCC), the output currents of the DESSs follow the relationship:

$$
\sum i_{D E S S, i}(t)=i_{e x c}(t)
$$

where $\mathrm{i}_{\text {ext }}(\mathrm{t})$ is the aggregated exchange current of the all DESSs at the PCC. It can be assumed that the voltage drop caused by dc transmission lines can be neglected. Hence, the output voltage of DESSs can be approximated: $V_{d c i} \approx V_{d c 0}$ where $\mathrm{V}_{\mathrm{dc} 0}$ is the common voltage at the PCC. By combining (2) and (3), and assuming that there are two distributed energy storage systems in the VPP, we have:

$$
\begin{gathered}
A V R_{1} i_{D E S S, 1}=A V R_{2} i_{D E S S, 2} \\
\frac{i_{D E S S, 1}}{i_{D E S S, 2}}=\frac{\Delta S O C_{1, \min }^{q}}{\Delta S O C_{2, \min }^{q}} \\
i_{D E S S, 1}=\frac{\Delta S O C_{1, \min }^{q}}{\sum_{i=1}^{2} \Delta S O C_{i, \min }^{q}} \times i_{e x c} \\
i_{D E S S, 2}=\frac{\Delta S O C_{2, \min }^{q}}{\sum_{i=1}^{2} \Delta S O C_{i, \min }^{q}} \times i_{e x c}
\end{gathered}
$$

Therefore, the aggregated exchange current can be dynamically shared according to $\mathrm{SOC}_{\mathrm{i}}$ of the DESSs. Considering (12), (13), (1) can be rewritten as: 


$$
\operatorname{SOC}_{i}(t)=\operatorname{SOC}_{i}(0)-\int_{0}^{t} \eta \frac{\Delta S O C_{i, \min }^{q}}{C_{B a t, i} \sum \Delta S O C_{i, \text { min }}^{q}} i_{e x t} d \tau
$$

\subsection{Effect of the Exponent Coefficient of SOC}

As discussed in section B, the SOC-balancing speed can be determined by selecting a suitable exponent coefficient $q$. In order to determine the accepted range of the exponent coefficient, the following constraints must be satisfied.

The initial output currents of DESSs can be written as:

$$
i_{D E S S, i}(t) \leq I_{\max , i}
$$

Due to the limitation of the maximum permitted output current of each DESS, it is obtained as

$$
\frac{\Delta S O C_{1, \min }^{q}}{\sum_{i=1}^{2} \Delta S O C_{i, \min }^{q}} \leq \frac{I_{\max , i}}{i_{e x c}}
$$

Inequality (16) will determine the first limitation of the exponent coefficient. If $q$ is larger than its upper limit, the output current of the DESS will exceed its maximum permitted current of the converter.

The second constraint that determines the exponent coefficient is the maximum permitted dc voltage deviation due to the droop control. Considering the DESS, ${ }_{1}$ for instance, the dc voltage deviation can be acquired from (2) as.

$$
\begin{aligned}
& \Delta V_{d c \text { min }, 1}=A V R_{\text {disch arg } e, 1} i_{D E S S, 1} \\
& \Delta V_{d c \min , 1}=K_{0} \frac{1}{\sum \Delta S O C_{\min , i}^{q}} i_{e x c} \\
& \Delta V_{d c \text { max }, 1}=A V R_{c h \arg e, 1} i_{D E S S, 1} \\
& \Delta V_{d c \text { max }, 1}=K_{0} \sum \Delta S O C_{\min , i}^{q} i_{e x c} \\
& \Delta V_{d c \text { min }, i} \leq \Delta V_{d c l o w e r, i} \\
& \Delta V_{d c \max , i} \leq \Delta V_{d c u p p e r, i}
\end{aligned}
$$

where $\Delta \mathrm{V}_{\text {dclower, } \mathrm{i}}, \Delta \mathrm{V}_{\text {dcupper,i }}$ are the maximum deviation of the dc voltage in discharge and charge process respectively, and can be calculated as:

$$
\begin{gathered}
\Delta V_{d c l o w e r, i}=V_{d c r e f}-V_{d c \min , i} \\
\Delta V_{d c u p p e r, i}=V_{\text {max }, i}-V_{d c r e f, i}
\end{gathered}
$$

From (18), (19), (21) and (22), it yields:

$$
i_{\text {exc }} \frac{K_{0}}{\Delta V_{\text {dclower }, i}} \leq \sum \Delta S O C_{\min , i}^{q} \leq \frac{\Delta V_{d c u p p e r, i}}{K_{0} i_{\text {ext }}}
$$


It can be assumed that the exchange current is caused by the increase load with the resistance $R_{L}$, (23) can be rewritten as:

$$
i_{e x c}=\frac{V_{d c r e f}-\Delta V_{d c \min , i}}{R_{L}}
$$

Hence, (18) can be rewritten as:

$$
\Delta V_{d c \text { min }, 1}=K_{0} \frac{1}{\sum \Delta S O C_{\text {min }, i}^{q}} \times \frac{V_{d c r e f}-\Delta V_{d c \text { min }, i}}{R_{L}}
$$

Solving (27), it yields

$$
\Delta V_{d c \min , 1}=\frac{K_{0} V_{d c r e f}}{R_{L} \sum \Delta S O C_{\min , i}^{q}+K_{0}}
$$

It is obviously seen that (28) is an increasing function of $q$, when other parameters are assumed as constant. Thus, to achieve inequality (21), the exponent coefficient should be less than its upper limit.

On other hand, the lower limit of the exponent coefficient is determined by minimizing the difference of SOCs within the acceptable time duration. From (14), taking the derivative of $\mathrm{SOC}_{1}$ and $\mathrm{SOC}_{2}$, it can be derived as.

$$
\frac{d S O C_{1}}{\Delta S O C_{1}^{q}}=K \frac{d S O C_{2}}{\Delta S O C_{2}^{q}}
$$

where $K$ is expressed as:

$$
K=\frac{\eta_{1} C_{B a t, 2}}{\eta_{2} C_{B a t, 1}}
$$

It is noted that $q$ is chosen larger than 1 because of improving the SOC-balancing speed. Hence, by solving the differential equation (29), it yields

$$
\frac{1}{1-q}\left(\Delta S O C_{1}^{1-q}-K \Delta S O C_{2}^{1-q}\right)=\left.\frac{1}{1-q}\left(\Delta S O C_{1}^{1-q}-K \Delta S O C_{2}^{1-q}\right)\right|_{t=0}
$$

Then, it can be arranged as

$$
\left(\frac{\Delta S O C_{1}}{\Delta S O C_{2}}\right)^{1-q}=K+\frac{\left.\left(\Delta S O C_{1}^{1-q}-\Delta S O C_{2}^{1-q}\right)\right|_{t=0}}{\Delta S O C_{2}^{1-q}}
$$

It is assumed that $\operatorname{SOC}_{1}(0)$ is larger than $\operatorname{SOC}_{2}(0)$. It is desired that after the scheduled time duration $\mathrm{T}$, the difference between $\mathrm{SOC}_{1}$ and $\mathrm{SOC}_{2}$ is smaller than $\varepsilon$. In other word, $\varepsilon$ is the variable representing the SOC-balancing accuracy. The acceptable SOC-balancing accuracy $\varepsilon$ should be obtained within the time duration $\mathrm{T}$. Then, it yields:

$$
\left.\left(S O C_{1}-S O C_{2}\right)\right|_{t=T} \leq \varepsilon
$$

From (33) it can be rewritten as

$$
\left.\left(\left(S O C_{1}-S O C_{\text {min }}\right)-\left(S O C_{2}-S O C_{\text {min }}\right)\right)\right|_{t=T} \leq \mathcal{E}
$$




$$
\left.\frac{\Delta S O C_{\min , 1}}{\Delta S O C_{\min , 2}}\right|_{t=T} \leq 1+\varepsilon
$$

It is also noted that:

$$
\left.\frac{S O C_{1}}{S O C_{2}}\right|_{t=T} \geq 1 \text { and } 1-q<0
$$

Therefore, from (35) and (36), it can be drawn that:

$$
(1+\varepsilon)^{1-q} \leq K+\frac{\left.\left(\Delta S O C_{1}^{1-q}-\Delta S O C_{2}^{1-q}\right)\right|_{t=0}}{\left.\Delta S O C_{2}^{1-q}\right|_{t+T}}
$$

Consequently, the lower limitation of the $q$ can be achieved by solving the inequality (37).

It should be noted that the SOCs of DESSs cannot be smaller than their minimum values. The DESSs should operate with SOC in the proper range from $\mathrm{SOC}_{\text {low }}$ to $\mathrm{SOC}_{\text {high. }}$. Fig. 3 shows the AVR and SOC waveforms for the proposed control method with different $q$ in charge and discharge process.

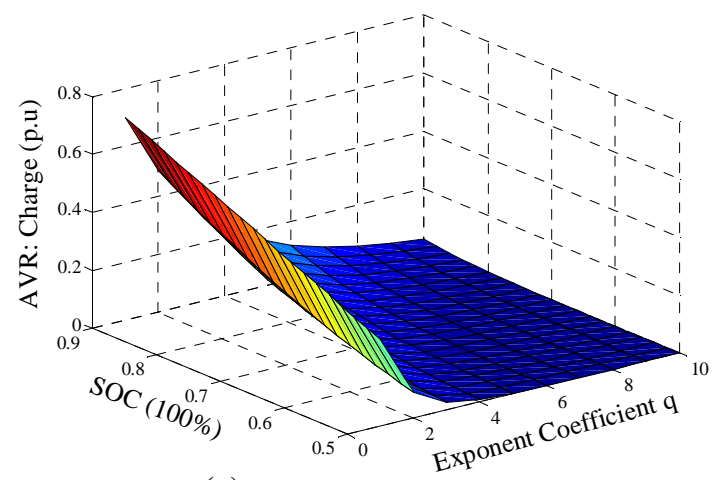

(a)

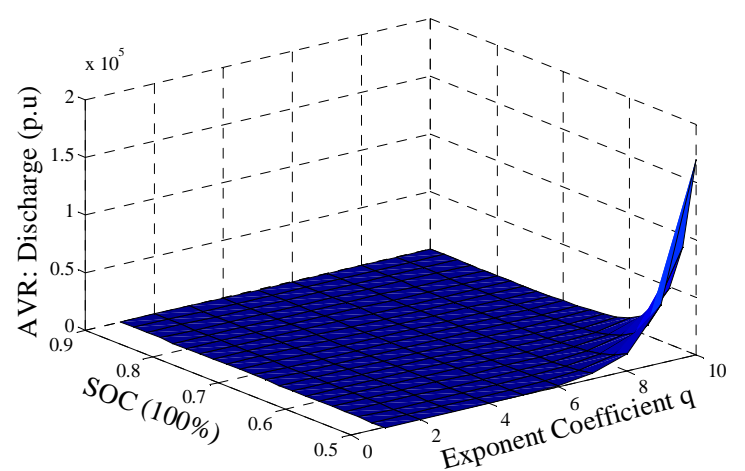

(b)

Figure 3. Dependence of AVR in charge (a) and discharge (b) process on SOC of battery and coefficient $q$.

\section{SIMULATION RESULTS}


Several scenarios will be simulated in MATLAB to verify the proposed control method. The parameters of the system as in Figure 1 are provided in Appendix.

Case 1: Performance of the proposed control method with different exponent coefficient $q$

It is assumed that VPP has two BESSs and discharge the load of $400 \mathrm{~kW}$. The initial values of SOC1 and SOC2 are 0.9 and 0.8 respectively. As a result, Figure 4 shows waveforms of the SOCs and output powers of BESSs during discharge process. It is seen that larger $q$ leads to shorter time for achieving the balancing SOC, thus faster equalization of the output powers of BESSs.

Case 2: Performance of the proposed control method with different initial SOCs

In the first case-study, the difference between $\mathrm{SOC}_{1}$ and $\mathrm{SOC}_{2}$ is 0.1 . In order to realize the proposed method with range of difference $\mathrm{SOCs}$, the initial $\mathrm{SOC}_{1}$ is fixed at 0.9 and the initial SOC2 is changed from 0.8 to 0.4 . It is seen that equalization of SOCs can be achieved within this method as shown in Figure 5.

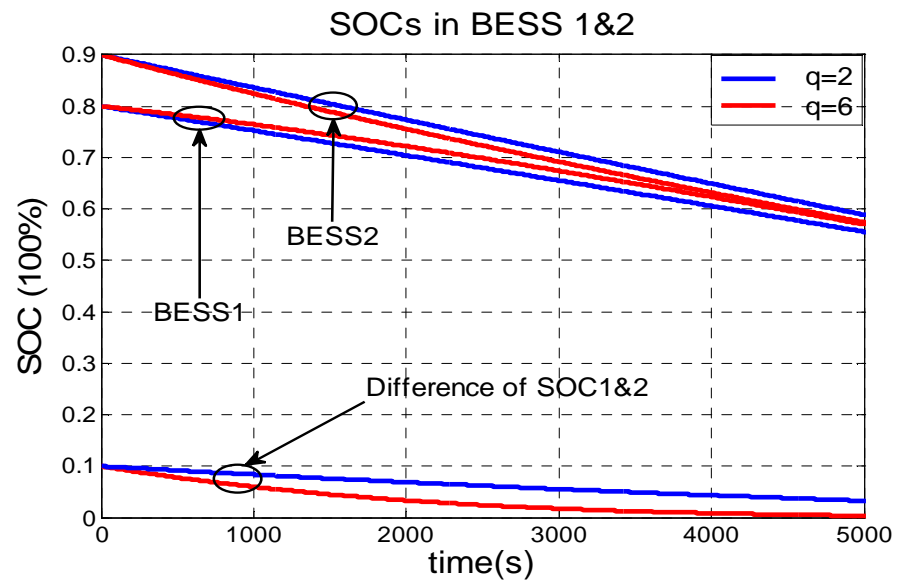

(a)

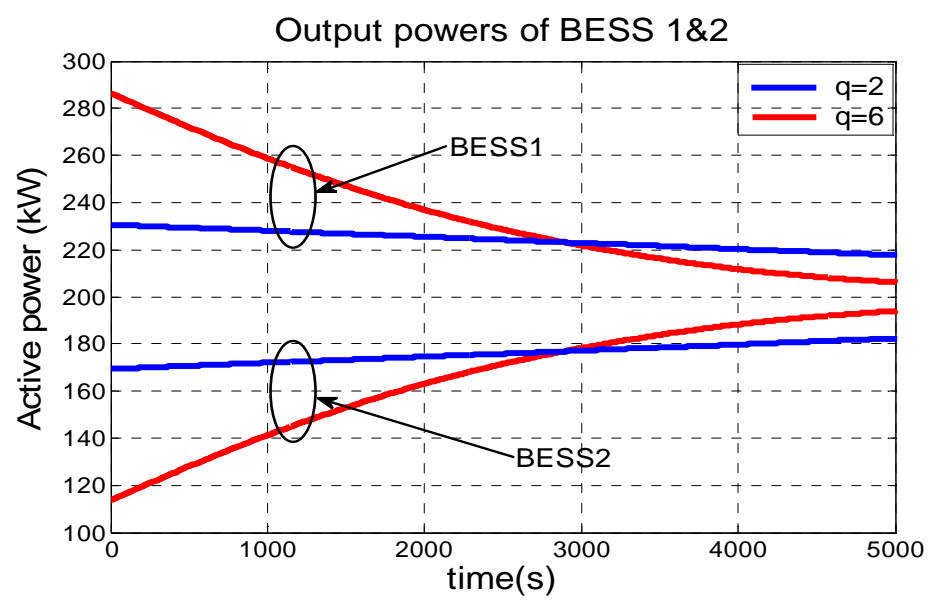

(b)

Figure 4. Curves of SOC and power sharing waveforms for two BESS under the proposed control method with different q. (a) Curves of SOCs; (b) Curves of output powers of BESSs.

Case 3: Validation of the proposed control method consideration the estimated errors 
It is reported that there is error in estimation of SOC [20]. Therefore, the method should be tested with consideration estimated error of SOC. In Figure 6, the waveforms of SOCs and output powers of BESSs are depicted. It is seen that the proposed method is valid for different errors.

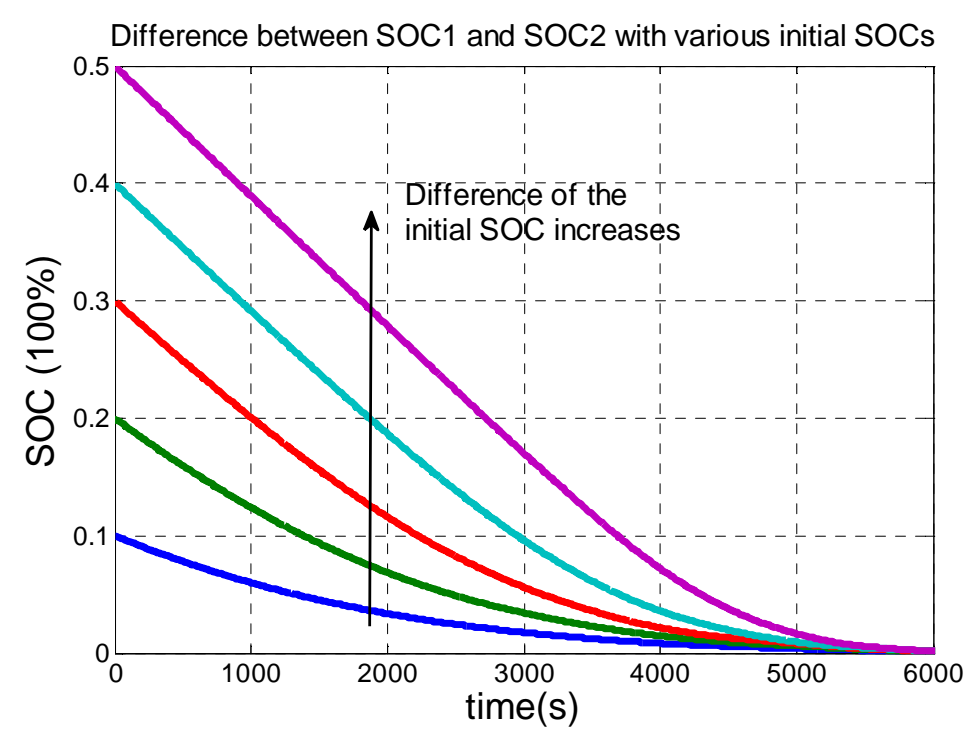

(a)

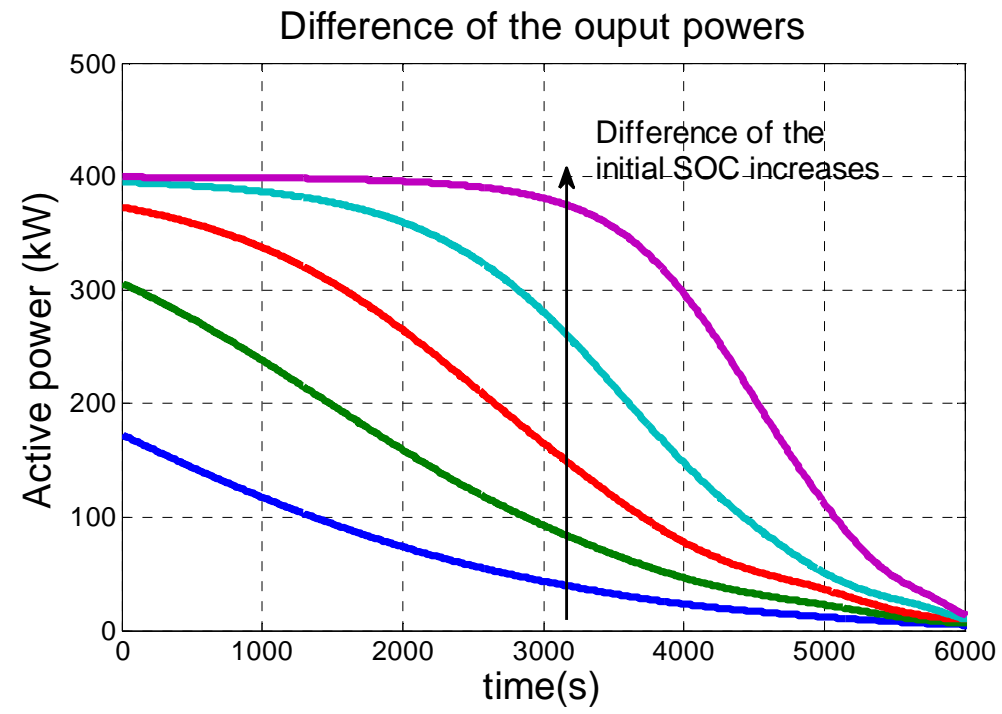

(b)

Figure 5. Waveforms of the SOC difference and output power difference with various initial SOCs. (a) Waveforms of the SOC difference; (b) Output power difference. 


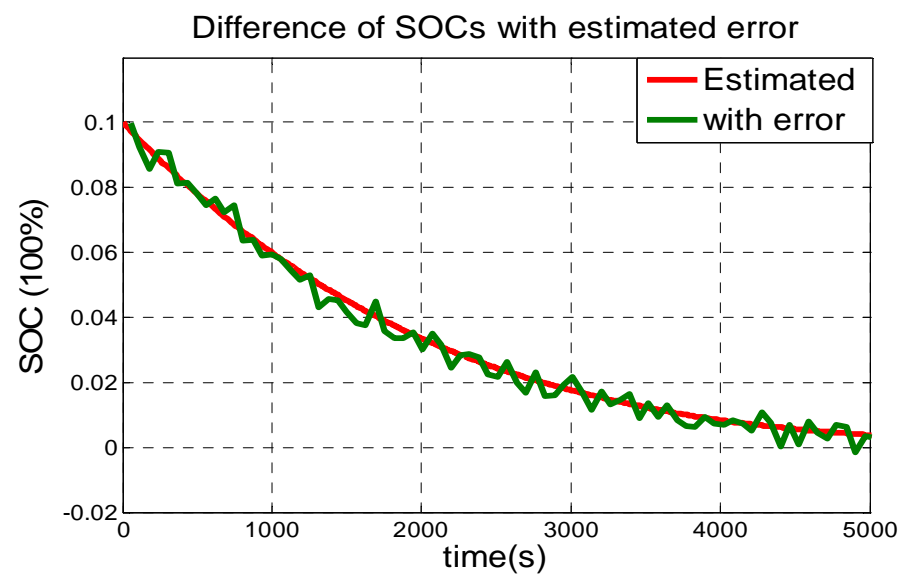

(a)

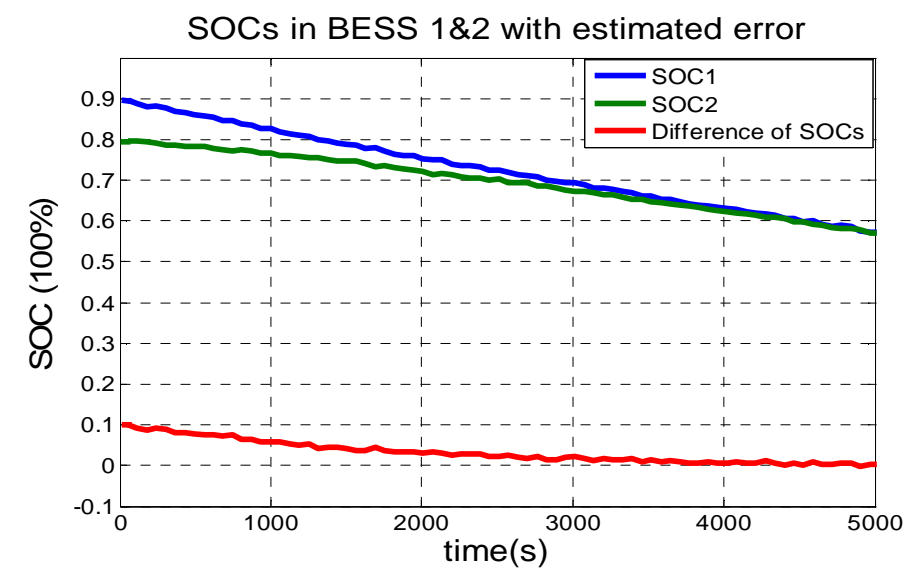

(b)

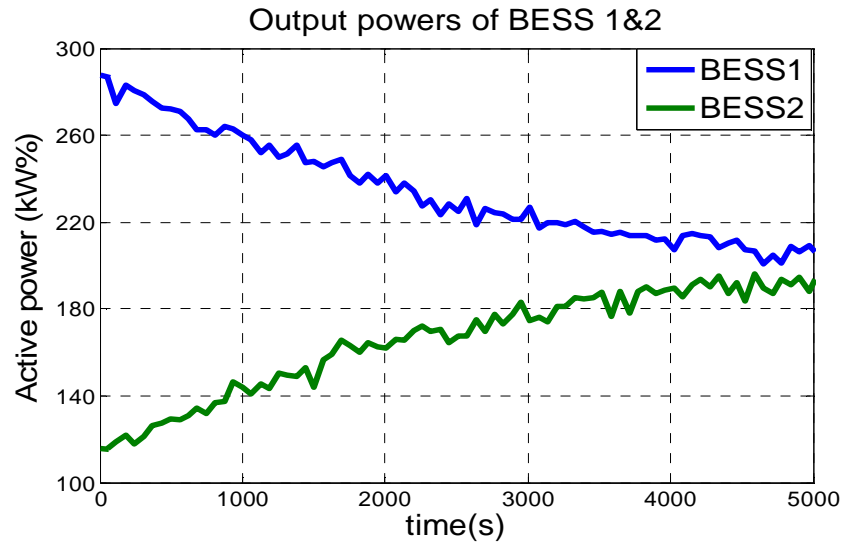

(c)

Figure 6. SOC and power sharing waveforms with consideration estimated errors: (a) Waveforms of SOC estimated and with errors; (b) Waveforms of SOCs with errors; (c) Waveforms of output powers with estimated errors. 


\section{CONCLUSIONS}

In this research, the proposed control method based on SOC is presented in order to improve the lifetime of DBESs in VPP applications. The speed of SOC balancing can be determined according to the exponent function and automatically changed based on the real-time SOC. Within this method, the BESS with lower SOC will discharge less power and charge more power, while the ones with higher SOC will charge less power and discharge more power. This proposed control method is a decentralized control solution for long-term management of multibatteries in VPP applications.

\section{APPENDIX}

Table A. Parameters of the case-study system.

\begin{tabular}{c|c|c|c}
\hline \hline Item & Symbol & Value & Unit \\
\hline Initial value of SOC1 & SOC1 $(0)$ & 90 & $\%$ \\
\hline Initial value of SOC2 & SOC2 $(0)$ & 80 & $\%$ \\
\hline DC voltage of BESS1 & Vdc, 1 & 480 & V \\
\hline DC voltage of BESS2 & Vdc 2 & 480 & V \\
\hline Load Resistance & RL & 200 & $\Omega$ \\
\hline Load Power & PL & 1800 & W \\
\hline Power Rating of the BESS & Prate & 2500 & W \\
\hline \hline
\end{tabular}

\section{REFERENCES}

1. Awerbuch, S., Preston, A. - The Virtual Utility: Accounting, Technology \& Competitive Aspects of the Emerging Industry. Kluwer Academic Publishers, Massachusetts, USA, 1997.

2. Dielmann, K., and van der Velden, A. - Virtual Power Plants (VPPs)-A New Perspective for Energy Generation?'. Modern Techniques and Technologies (MTT) 2003. Proc. 9th Int. Scientific and Practical Conference of Students, Post-graduates and Young Scientists, 7-11 April 2003, pp. 18-20.

3. Caldon, R., Rossi Patria, A., and Turri, R. - Optimal Control of a Distribution System with a Virtual Power Plant. Bulk Power System Dynamics and Control - VI, Cortina d'Ampezzo (ITA), 22-27 August 2004.

4. Boroyevich D., Igor C., Dong D., Burgos R., Wang F., Lee F. - Future electronic power distribution systems-A contemplative view, 12th International Conf. on Optimization of electrical and electronic equipment 2010.

5. Willems, B. - Physical and Financial Virtual Power Plants, April 2005. Available at http://citeseerx.ist.psu.edu/viewdoc/download;jsessionid=909683076720C2D3B34253E2 0457F967?doi=10.1.1.511.5916\&rep=rep1\&type=pdf.

6. Platts, 'Saar Targets Balancing Market', Power in Europe no. 446, 2005, p. 16.

7. Department for Trade and Industry, "Reducing the Cost of System Intermittency Using Demand Side Control Measures,” DTI, London, 2006.

8. Smith S. C., Sen P. K., Kroposki B. - Advancement of Energy Storage Devices and Applications in Electrical Power System, in Proc. 2008 IEEE Power and Energy Society 
General Meeting - Conversion and Delivery of Electrical of Electrical Energy in the 21th Century.

9. Ibrahim H., Ilinca A., Perron J. - Conversion and Analysis of Different Energy Storage Techniques Based on their Performance Index, in Proc. Electrical Power Conf. (EPC 2007), IEEE Canada, 2007

10. Qian K., Zhou C., Li Z., Yuan Y. - Benefits of Energy Storage in Power Systems with High Level of Intermittent Generation, in Proc. 20th International Conf. on Distribution Part 1 (CIRED 2009). Prague, Czech Republic 2009.

11. Ki-Hyeok K., Dong-Jun W. - Power Management Strategy of Stand-Alone Hybrid System to reduce the operation mode changes, Transmission \& Distribution Conference \& Exposition: Asia and Pacific, pp. 1-4, Oct. 2009.

12. Van Voorden A. M., Paap G. C. - The Use of Batteries in Stand-alone Renewable Power Systems, Power Tech, 2005 IEEE Russia.

13. 13]Park H. -S., Kim C. E., Kim C. -H., Moon G. -W. and Lee J. -H. - A modularized charge equalizer for an HEV Lithium-Ion battery string, IEEE Trans. Ind. Electron. 56 (5) (2009) pp. 1464-1476.

14. Manenti A., Abba A., Merati A., Savaresi S. M. and Geraci A. - A new BMS architecture based on cell redundancy, IEEE Trans. Ind. Electron. 58 (9) (2011) pp. 4314-4322.

15. Kim J., Shin J., Chun C. and Cho B. H. - Stable configuration of a Li-Ion series battery pack based on a screening process for improved voltage/SoC balancing, IEEE Trans. Power Electron. 27 (1) (2012) pp. 411-424.

16. Maharjan L., Inoue S., Akagi H. and Asakura J. - State-of-charge (SOC) - balancing control of a battery energy storage system based on a cascade PWM converter, IEEE Trans. Power Electron. 24 (6) (2009) pp. 1628-1636.

17. Zhou H., Bhattacharya T., Duong T., Siew T. S. T. and Khambadkone A. M. - Composite energy storage system involving battery and ultracapacitor with dynamic energy management in microgrid applications, IEEE Trans. Power Electron. 26 (3) (2011) pp. 923-930.

18. Salameh Z. M., Casacca M. A., Lynch A. - A mathematical model for lead-acid batteries, IEEE Trans. Energy Conversion 7 (1) (1992) page(s) 93C98.

19. Dragicevic T., Guerrero J. M., Vasquez J. C., Skrlec D. - Supervisory Control of an Adaptive-Droop Regulated DC Microgrid with Battery Management Capacity, IEEE Trans. On Power Electronics 29 (2) (2014) pp. 695-706.

20. He H., Xiong R., Zhang X., Sun F., and Fan J.X. - State of Charge Estimation of the Lithium-Ion Battery Using an Adaptive Extended Kalman Filter Based on an Improved Thevenin Model, IEEE Trans. On Vehicular Technology 80 (4) (2011) pp. 444-470.

21. Duc N. H., and Hung T. N. - Adaptive coordinated droop control for multi-battery storage, IEEE EURCON 2015, Spain, 2015.

22. Duc N. H. - An adaptive Control of hybrid battery-supercapacitor storage for integration of wind and solar, 2016 IEEE International Conf. on Sustainable Energy Technologies (ICSET), 2016. 